\title{
A Novel Control Strategy for PV/Wind/Battery Hybrid System Using High Gain Boost Converter
}

\author{
Grandhi N L N Rajesh $^{1}$ | K Ravi Kumar ${ }^{2}$ \\ ${ }^{1}$ PG Scholar, Department of EEE, Priyadarshini Institute of Technology \& Science, Chintalapudi, India. \\ ${ }^{2}$ Associate Professor \& HOD, Department of EEE, Priyadarshini Institute of Technology \& Science, Chintalapudi, India.
}

To Cite this Article

Grandhi N L N Rajesh and K Ravi Kumar, "A Novel Control Strategy for PV/Wind/Battery Hybrid System Using High Gain Boost Converter", International Journal for Modern Trends in Science and Technology, Vol. 07, Issue 03, March 2021, pp.: 295-303.

\section{Article Info}

Received on 14-February-2021, Revised on 15-March-2021, Accepted on 22-March-2021, Published on 26-March-2021.

\section{ABSTRACT}

In this paper, a classic proportional-integral (PI) control strategy as an energy management strategy (EMS) and a microgrid stand-alone power system configuration are proposed to work independently out of grid. The proposed system combines photovoltaics (PVs), and Battery. The system supplies a dump load with its demand power. The system includes DC/DC and DC/AC converters, as well as a maximum power point tracking (MPPT) to maximize the harvested energy from PV array. The classic PI control strategy is used to control the main system parameters like state-of-charge (SOC) for the battery. The corresponding energy management and control strategy are proposed to realize the power balance among three ports in different operating scenarios, which comprehensively takes both the maximum power point tracking (MPPT) benefit and the battery charging/discharging management into consideration. The simulations are conducted using the Matlab/Simulink software to verify the operation performance of the proposed PV/battery hybrid distributed power generation system with the corresponding control algorithms, where the MPPT control loop, the battery charging/discharging management loop are enabled accordingly in different operating scenarios.

KEYWORDS: DC microgrid; energy management; hybrid power system; energy efficiency, Induction motor drive, EV Application

\section{INTRODUCTION}

In power system grids, the microgrid is identified as a distributed energy system (DES), including generators, energy storage elements like batteries (B) and supercapacitors to balance the generated power and the consumed power [1-3], an energy management system to control the entire operation of the microgrid sources [4,5], and load. All of these items are combined together and work in parallel with the utility grid, or out of grid as a stand-alone system used for a small area and few consumers [6,7]. Generally, the microgrid is considered a cluster of the utility grid [8], as shown in Figure 1. Using a utility grid for power distribution has some disadvantages, 0073uch as transmission losses, especially when the generating plants are far away from the consumers, bad environmental impact because of emission, and climate change due to the use of conventional resources in the generation phase. Microgrids represent an alternative option that has the potential to overcome these problems. Microgrids can minimize power losses through transmission, reduce $\mathrm{CO} 2$ emissions, and limit climate change, especially when using renewable energy resources in electricity generation. It also saves money in several ways, such as preventing outage, selling electricity to national grids through feed, and tariff or net metering systems. Using 
power systems that combine renewable sources with zero emission besides energy storage elements makes the system able to achieve maximum efficiency compared to systems containing conventional sources [9-11]. An energy management system is a system that controls the operation of the microgrid (MG) system. It uses many approaches and control strategies to get maximum system performance. These control strategies may include a state machine, a classic proportional-integral (PI) control, a fuzzy logic control, an external energy maximization, an equivalent minimization, and a frequency decoupling control strategy [12].

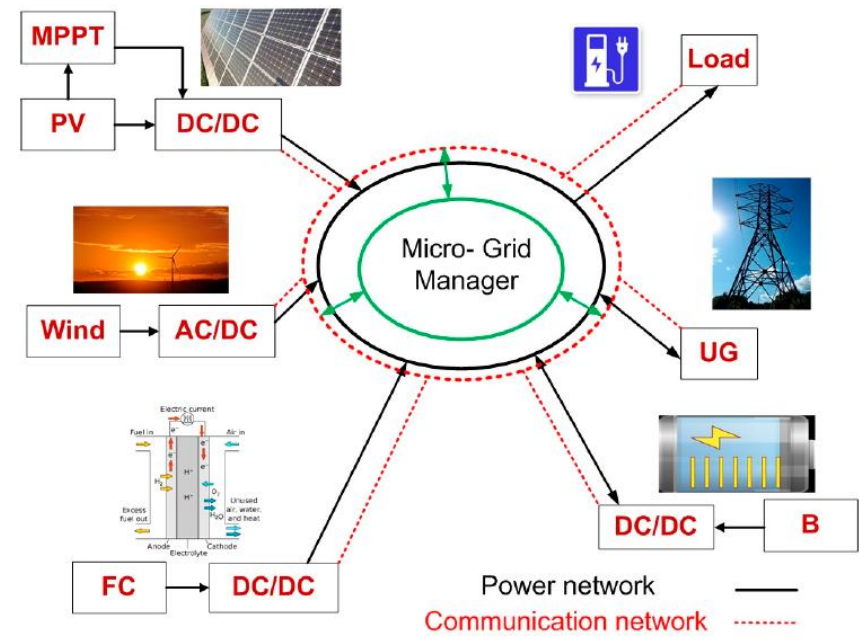

Figure 1. Configuration of DC microgrid

Manoj et al. [13] discussed the two main types of MG: Alternative current microgrid (ACMG) and direct current microgrid (DCMG). The DCMG has some advantages over the ACMG, such as high e_ciency, easy connection on the DC bus, and system reliabilities. They confirmed that in DCMGs, there are three factors influencing power disturbance: Fluctuation of power exchange, power variation between the storage system and the power sources, and the fast change in the DC bus load.

Ravichandrudu et al. [14] designed an MG system using renewable sources, which has the benefits of utilizing renewable energy sources and reducing transmission losses when using wind and hydro.

\section{MODEL OF PV CELL}

The solar cell can be modeled as a silicon diode which produces voltage when light is illuminated on it. Solar cells are constant current sources and can be represented as shown in the Fig1

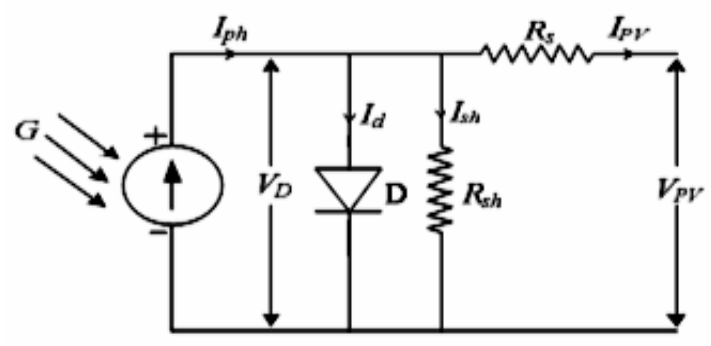

Fig1:mathematical model of PV cell

PV panel is modelled using mathematical equations (1)-(6) as given below

The current from PV panel is given by

$$
I_{p v}=I_{p h}-I_{d}-I_{s h}
$$

Where $\quad \mathrm{I}_{\mathrm{pv}}=$ Current from PV panel

$=$ Photo generated Current

$$
\mathrm{I}_{\mathrm{d}}=\text { Diode current }
$$

$\mathrm{I}_{\mathrm{sh}}=$ Shunt current

The Photo generated current is given by

$I p h=G \times\left(I s c+\left(K_{i} \times\left(T_{o p}-T_{r e f}\right)\right)\right)$

Where $\mathrm{G}=\operatorname{Irradiation}\left(\mathrm{w} / \mathrm{m}^{2}\right)$

$\mathrm{I}_{\mathrm{sc}}=$ Short circuit Current

$\mathrm{K}_{\mathrm{i}}=$ Temp.Coefficient of $\mathrm{I}_{\mathrm{sc}}\left(2.2^{*} 10^{-23}\right)$

$\mathrm{T}_{\mathrm{op}}=$ Operating Temperature in ${ }^{\circ} \mathrm{C}$

$\mathrm{T}_{\text {ref }}=$ Reference Temperature $\left(25^{\circ} \mathrm{C}\right)$

The diode current is given by

$$
I_{d}=I_{s} \times\left(e^{q \times\left(\frac{V_{p v}+I_{p v} \times R s}{N s \times n \times V_{t} \times c}\right)}-1\right)
$$

Where Is $=$ Saturation Current

$\mathrm{V}_{\mathrm{pv}}=\mathrm{PV}$ Panel output voltage

$\mathrm{R}_{\mathrm{s}}=$ Series resistance $(0.01 \Omega)$

$\mathrm{V}_{\mathrm{t}}=$ Thermal Voltage $=\left(\frac{K * T o p}{q}\right)$

$\mathrm{n}=$ Ideality Factor (1-2)

$\mathrm{C}=$ Total no. of Cells

$\mathrm{N}_{\mathrm{s}}=$ No. of cells in series

$\mathrm{Q}=$ Charge of an electron $=1.602^{*} 10^{-19} \mathrm{C}$

$\mathrm{K}=$ Boltzmann Constant $=1.38^{*} 10^{-23}$

The saturation current is given by

$I_{s}=I_{r s} \times\left(\frac{T_{o p}}{T_{r e f}}\right) \times e^{\left(\frac{1}{T_{o p}}-\frac{1}{T_{r e f}}\right) \times\left(\frac{E_{g} \times q}{K \times n}\right)}$

Where the reverse saturation current is given by

$$
I_{r s}=\frac{I_{s c}}{e^{\left(\frac{q \times V_{o c}}{K \times C \times T_{o p} \times n}\right)}-\mathbf{1}}
$$

Where $\mathrm{E}_{\mathrm{g}}=$ Energy Gap of PV material $=1.12 \mathrm{ev}$

The shunt current is given by 
$I_{s h}=\left(\frac{V_{p v}+\left(I_{p v} \times R_{s}\right)}{R_{s h}}\right)$

The number of cells to be connected to form an array is considered by taking a practical PV Panel electrical data Table 1.The I-V and P-V characteristics of the modeled PV panel conform to the manufacturer data.

\section{ENERgy MANAGEMENT SYSTEM IN DC MICROGRID}

The proposed PV/battery hybrid distributed power generatiosystem is shown in Fig. 3.2. This is a three-port system interfacing a PV, an ESS unit (a battery for example) and a DCload. The battery serves as an energy buffer, which meansit can be charged or discharged to balance the power flowin the $\mathrm{PV} /$ battery hybrid power system. As shown in Fig. 2,the phase-shift full-bridge DC-DC converter interfacing thePV and the load shares power switches with the integratedbidirectional buck/boost converter interfacing the battery, based on which the power density of the system is enhanced compared with the conventional topology consisting of the independent phase-shift full-bridge DC-DC converter and bidirectional converter.

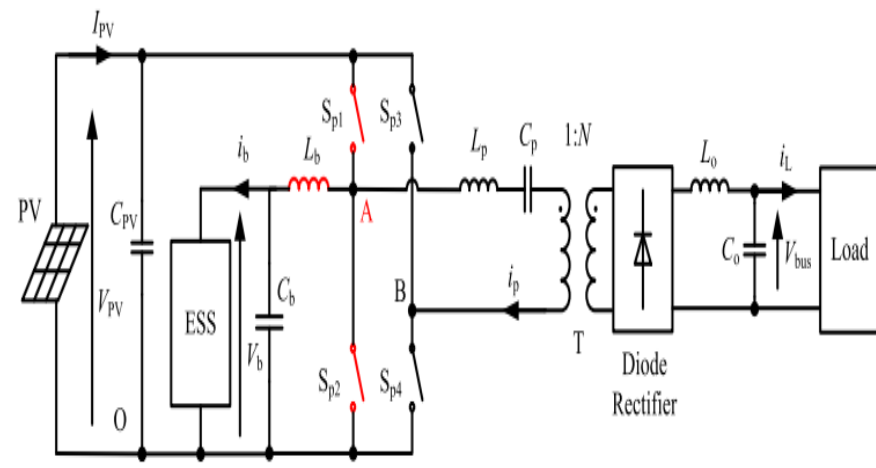

FIGURE 3.2. The proposed PV/battery hybrid distributed power generation system.

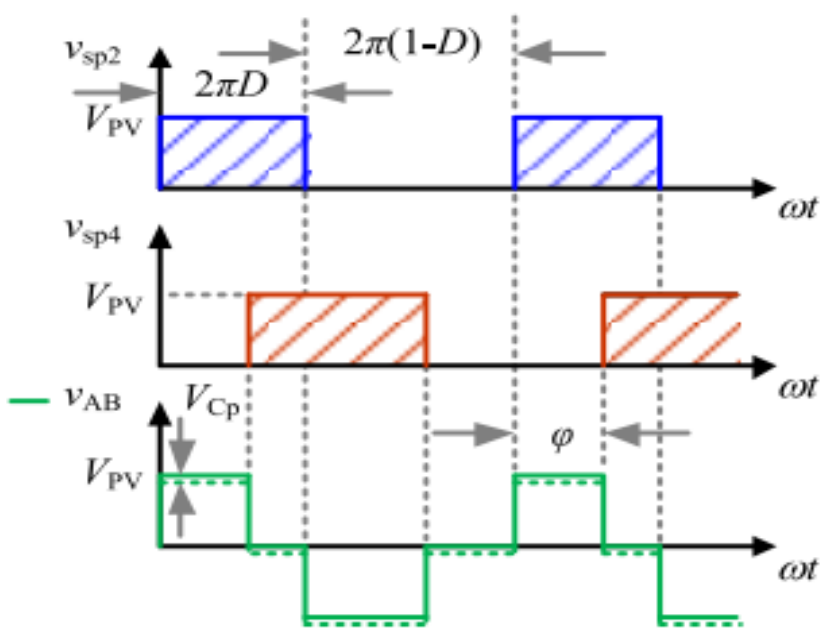

FIGURE 3.3. Modulation strategy of the full bridge with the phase shiftangle' and the duty cycle D.

A modified phase-shift modulation scheme is adopted forthe primary full bridge as shown in Fig. 3.3. Two switching legsof the primary full bridge are phase shifted by the angle '.In addition, the duty cycle of switches $\mathrm{Sp} 1$ and $\mathrm{Sp} 2$ on legA can be regulated, while the duty cycle of the other twoswitches is fixed at $50 \%$.

The integrated bidirectional buck/boost converter interfacing the battery at the primary side of the HF transformer ishighlighted in Fig. 3.2. The battery, capacitor $\mathrm{Cb}$, inductor Lb, two power switches of the leg A and the PV side bus forma bidirectional buck/boost topology inherently. When thebattery is charged with $\mathrm{ib}>0$, the topology operates in thebuck mode. When the battery is discharged with $\mathrm{ib}<0$, then the topology operates in the boost mode. Therefore, the bidirectional power flow can be achieved for the batterywith the charging/discharging management requirement. A flow diagram of the proposedcontrol algorithm is presented in Fig. 3.4

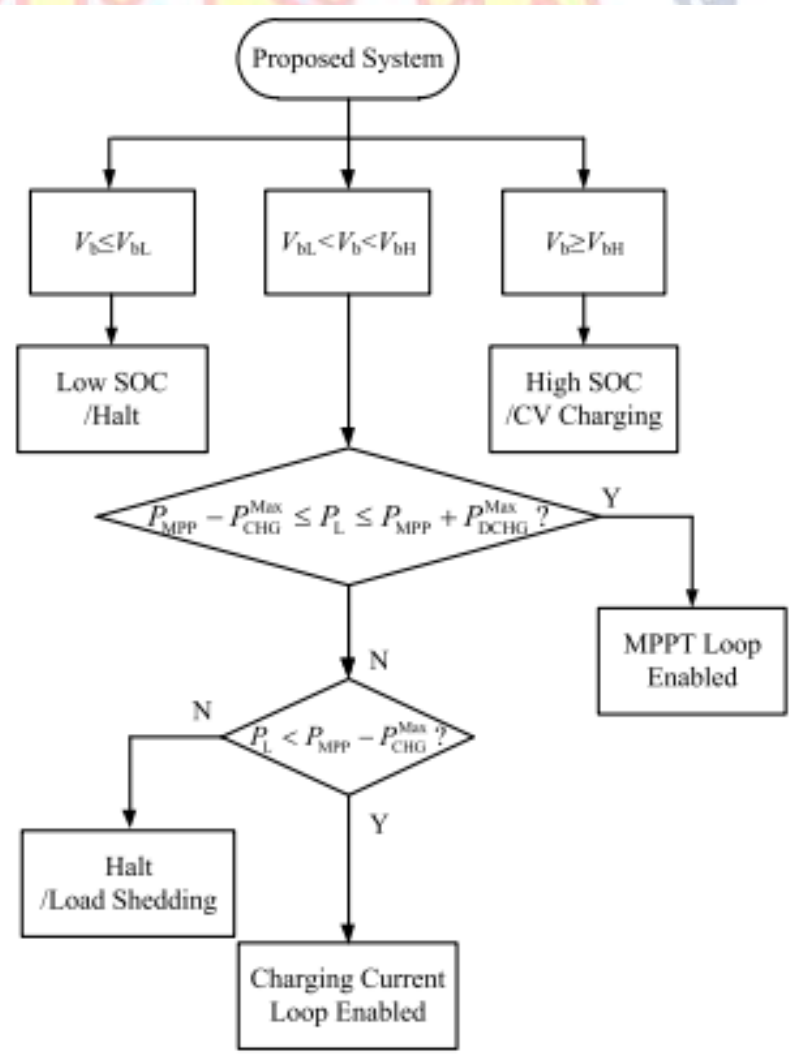

FIGURE 3.4.Flow diagram of the proposed control algorithm. 


\section{Proposed Three Port Converter fed INDUCTION MOTOR}

The three- phase induction machine is the most widely -used rotating machine in industry. Induction machines are almost always operated as motors due to undesirable characteristics as a generator. Single -phase induction motors are also very commonplace, being used for most household applications requiring a motor.

The induction motor speed variation can be easily achieved for a short range by either stator voltage control or rotor resistance control. But both of these schemes result in very low efficiencies at lower speeds. The most efficient scheme for speed control of induction motor is by varying supply frequency. This not only results in scheme with wide speed range but also improves the starting performance.

If the machine is operating at speed below base speed, then $\mathrm{v} / \mathrm{f}$ ratio is to be kept constant so that flux remains constant. This retains the torque capability of the machine at the same value. But at lower frequencies, the torque capability decrease and this drop in torque has to be compensated for increasing the applied voltage.

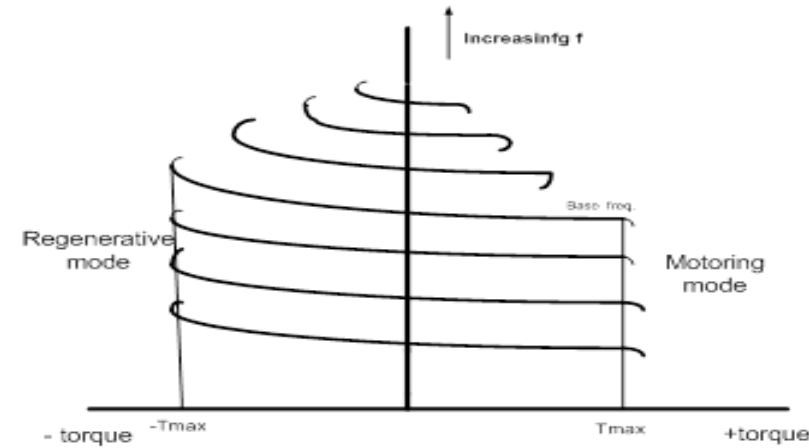

Fig.4.3 (a). Speed Torque Characteristics of Induction Motor with frequency variation

The above curve suggests that the speed control and braking operation are available from nearly zero speed to above synchronous speed.

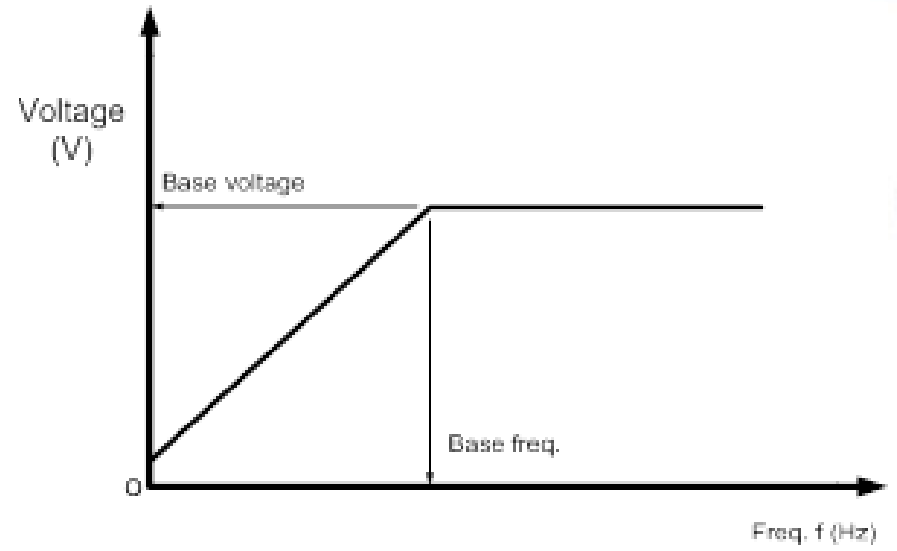

Fig.4.3 (b).voltage and frequency variation in VSI fed Induction motor
In Fig. 4.3 (b) it is noted that $\mathrm{V}$ is kept constant above base speed and freq. is increasing. The variable frequency control provides good running and transient performance because of the following features:

(a) Speed control and braking operation are possible from zero to above base speed.

(b) During transients (starting, braking and speed reversal), the operation can be carried out at the maximum torque with reduced current giving good dynamic response.

(c) Copper losses are reduced, efficiency and power factor are high as the operation is in between synch. speed and max. torque point at all frequencies.

(d) Drop in speed from no load to full load is small.

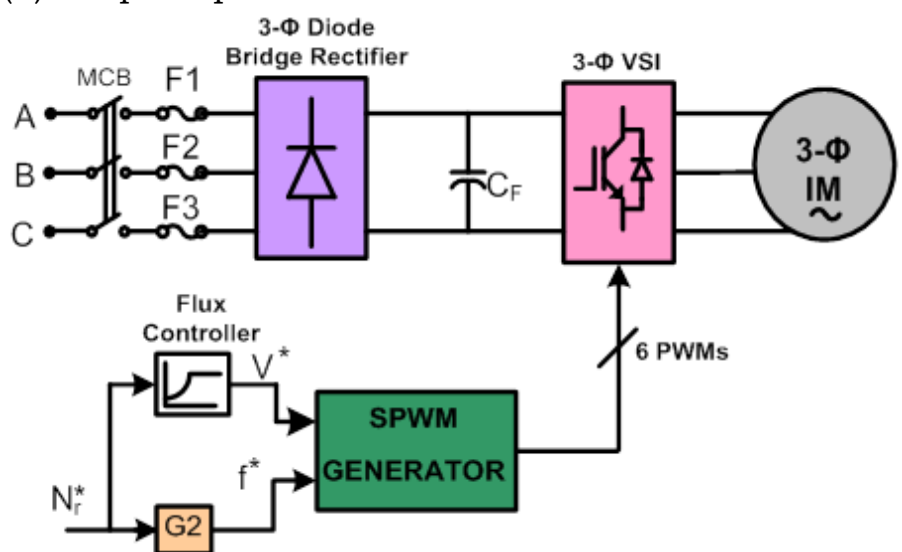

Fig:4.3 (c). Block Diagram Schematic of V/f control of VSI fed 3-phase Induction Motor drive Fig. 4.3 (c) shows the block diagram of a V/f control of VSI fed three phase induction motor drive. In this according to the reference speed input command $\left(\mathrm{N}_{\mathrm{r}}^{*}\right)$ the reference frequency $\left(\mathrm{f}^{*}\right)$ and reference voltage $\left(\mathrm{V}^{*}\right)$ commands are calculated such that $\mathrm{V} / \mathrm{f}$ ratio maintained to be constant. The reference commands $\mathrm{V}^{*}$ and $\mathrm{f}^{*}$ are given to the SPWM generator to generate 6-PWM pulses to the three-phase voltage source inverter which drives the three-phase induction motor.

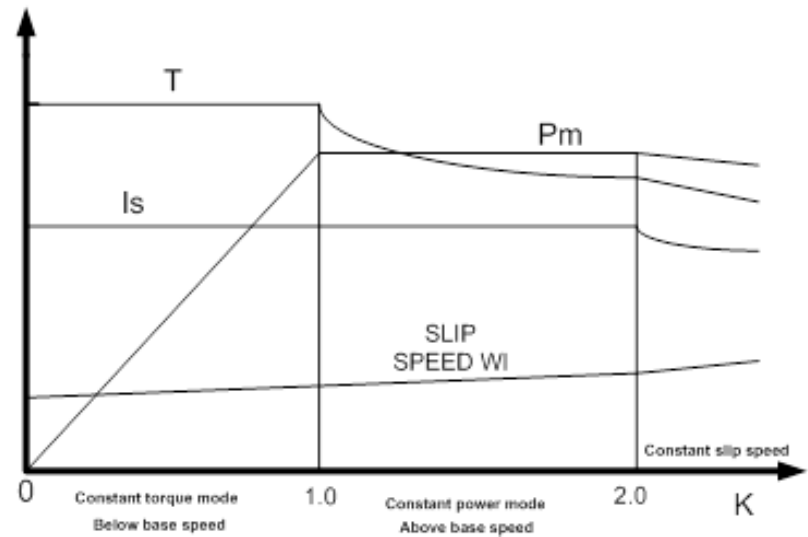

Fig.4.3(d). Modes of operation and variation of is, $\omega s 1$, T and Pm with per unit frequency 
V. Simulation Results

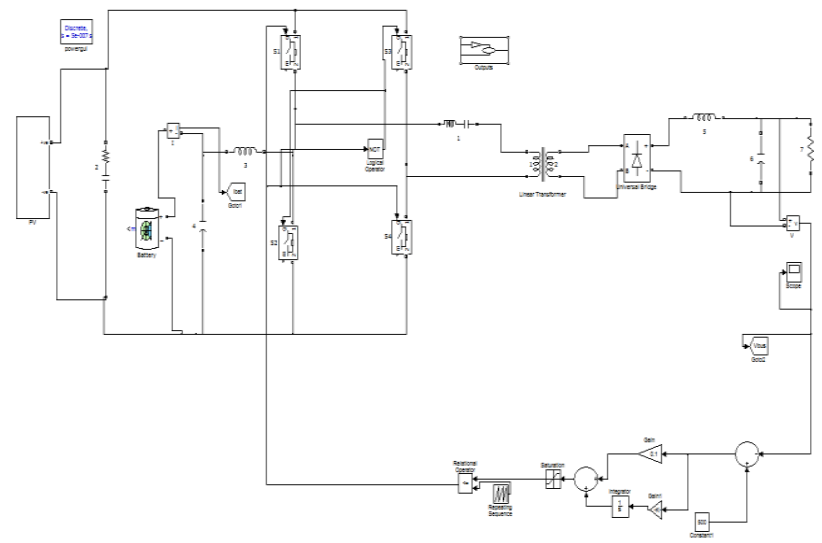

Fig 5.1 Diagram of Proposed System

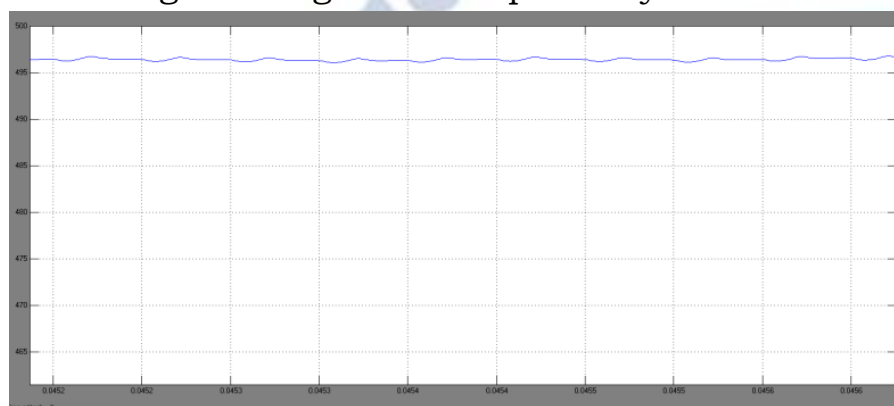

(a) $\mathrm{DC}$ bus voltage $\mathrm{V}$ bus;

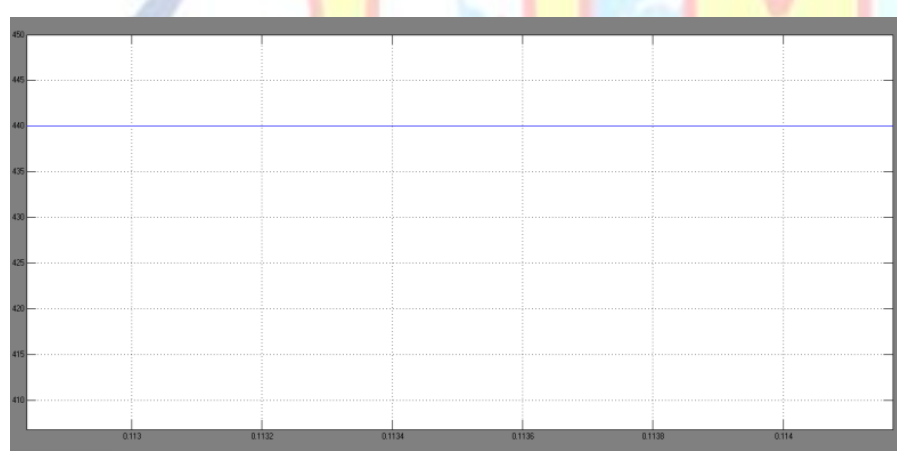

(b) PV voltage VPV;

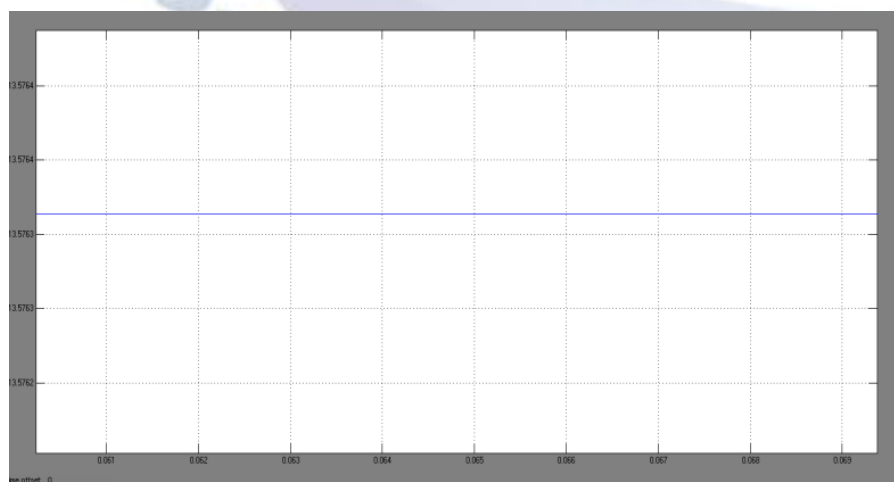

(c) PV current IPV;

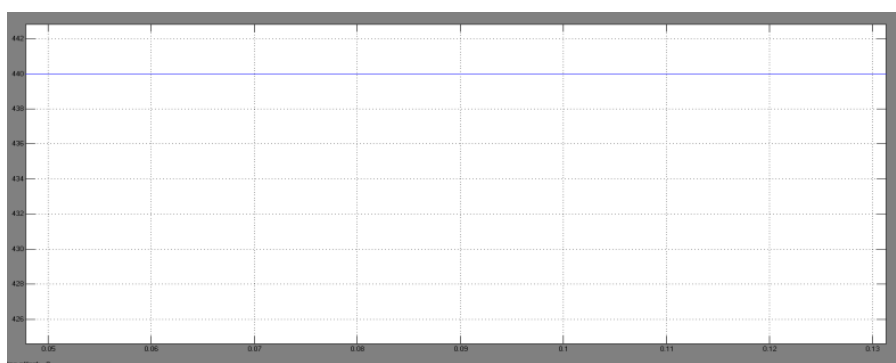

(d) PV reference voltage Vref;

FIGURE 5.2 Steady state simulation results of operation scenario 2. (a) DCbus voltage Vbus; (b) PV voltage VPV; (c) PV current IPV; (d) PV reference voltage Vref; (e) Batter charging current ib.

The steady state simulation results of the operation are shown in Fig. 5.2. The simulation conditions are asfollows: Irradiance D $1000 \mathrm{~W} / \mathrm{m} 2$, Temperature D $25{ }^{\circ} \mathrm{C}$ ), the load power PL D $10 \mathrm{~kW}$. By regulating the phase shiftangle' through a PI controller, the DC bus voltage Vbus iscontrolled at the present value Vbus* D $500 \mathrm{~V}$, which is shownin Fig. 5.2 (a). From Fig. 5.2 (b), Fig. 5.2 (c) and Fig. 5.2(d), sincethe MPPT loop is enabled in this scenario, the PV operates atthe maximum power point with VPV controlled near the idealvalue VMPP D $435 \mathrm{~V}$ and IPV controlled near the ideal valueIMPP D $22 \mathrm{~A}$. According to Fig. 5.2(e), the battery operates inthe discharging mode and supplies a part of the load power.

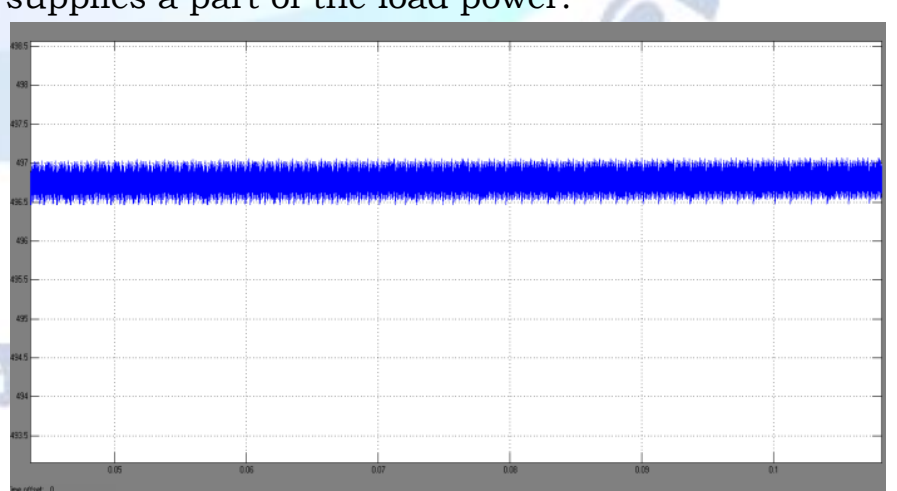

(a) DC bus voltage V bus; 
(b) PV voltage VPV;

present value Vbus* D $500 \mathrm{~V}$ as shown in Fig. 5.3 (a).From Fig. 5.3 (b), Fig. 5.3 (c) and Fig. 5.3 (d), the MPPT loopis also enabled in this scenario and the PV operates at themaximum power point with VPV controlled near the idealvalue VMPP D $435 \mathrm{~V}$ and IPV controlled near the ideal valueIMPP D 22 A. According to Fig. 5.3 (e), the battery operatesin the charging mode in this scenario and the surplus powerfrom the PV can be stored in the battery.

(c) PV current IPV;

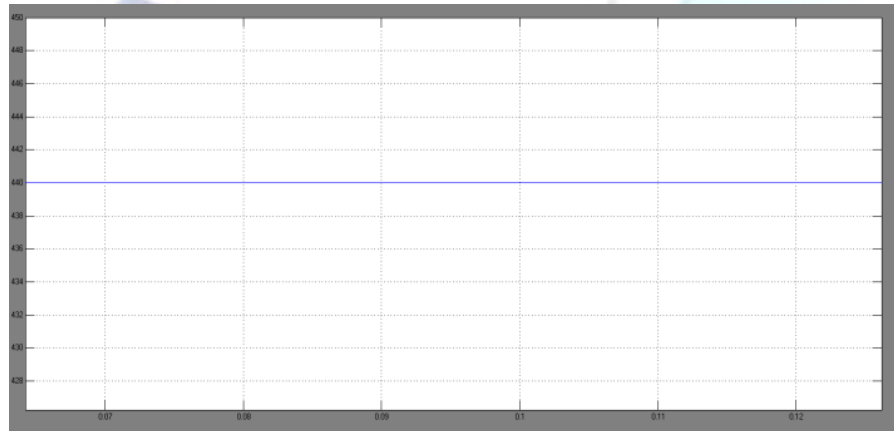

(d) PV reference voltage Vref;

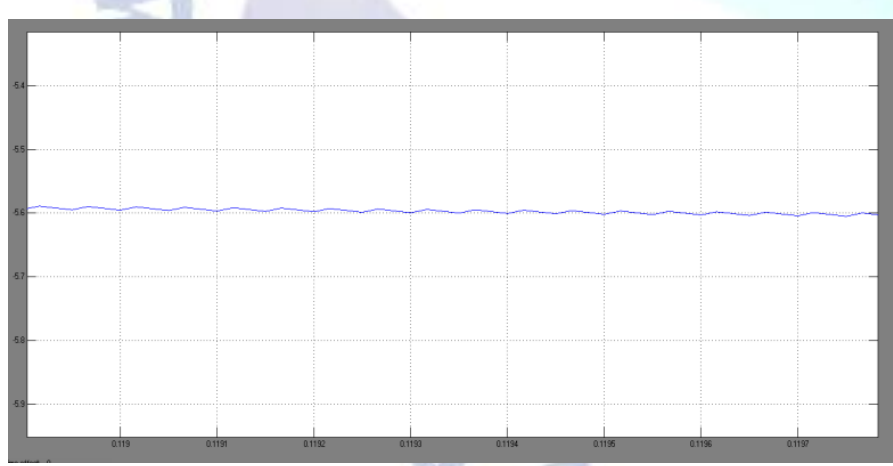

(e) Battery charging current ib.

FIGURE 5.3. Steady state simulation results of operation scenario 4. (a) DCbus voltage Vbus; (b)

PV voltage VPV; (c) PV current IPV; (d) PV referencevoltage Vref; (e) Battery charging current ib.

The steady state simulation results of the operation are shown in Fig. 5.3. The simulation conditions are asfollows: Irradiance D $1000 \mathrm{~W} / \mathrm{m} 2$, Temperature $\mathrm{D} 25^{\circ} \mathrm{C}$ ), the load power PL D $8 \mathrm{~kW}$. The DC bus voltage Vbus is controlled at the

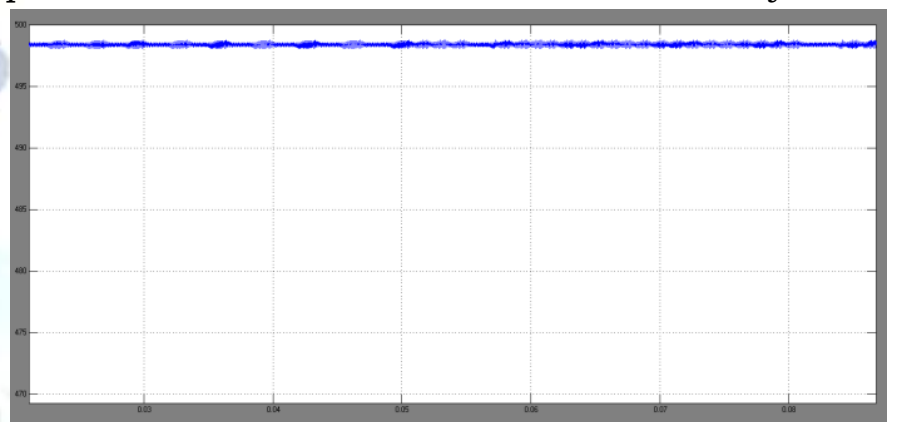

(a)
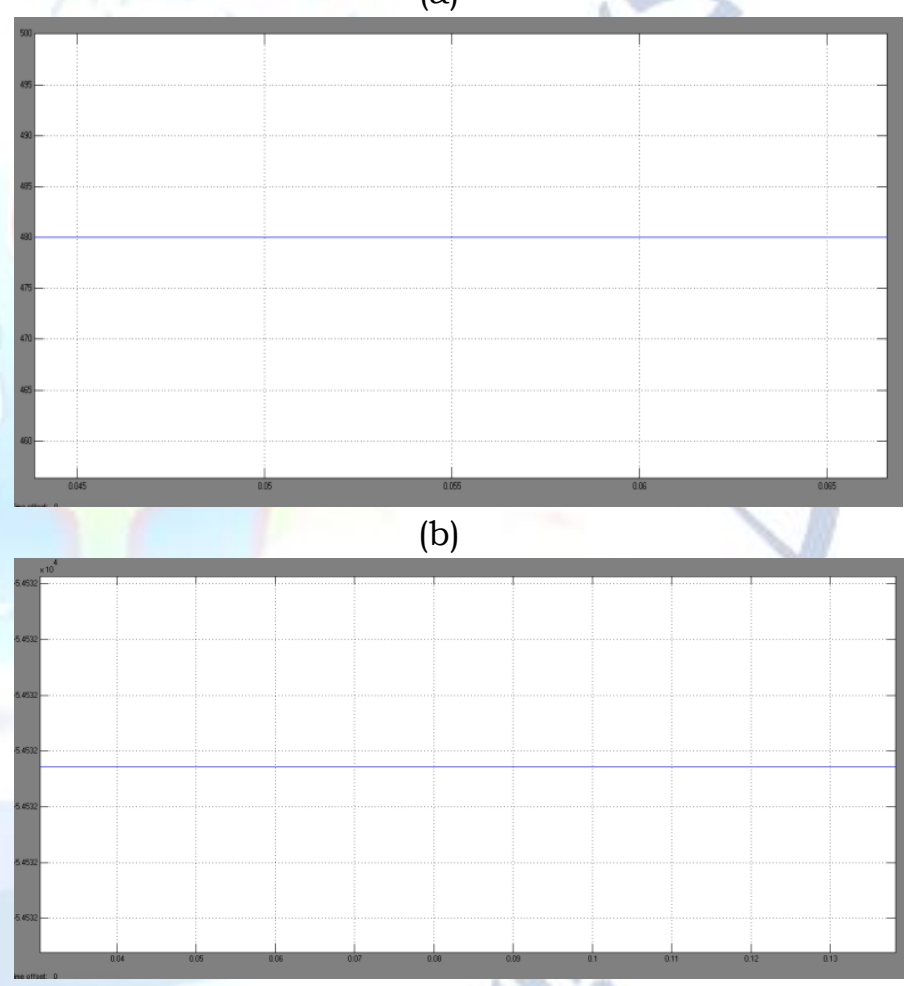

(c)

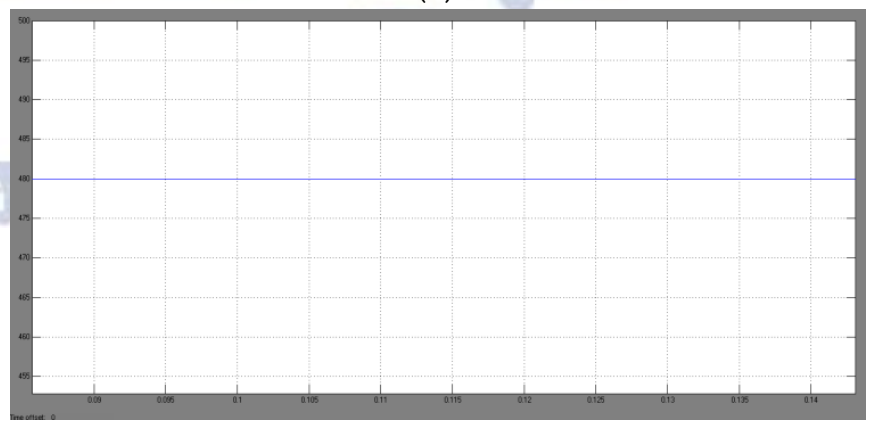

(d)

FIGURE 5.4 Steady state simulation results of operation scenario 5. (a) DCbus voltage Vbus; (b) 
PV voltage VPV; (c) PV current IPV; (d)

Batterycharging current ib

The steady state simulation results of the operation scenario5 are shown in Fig. 5.4. The simulation conditions are asfollows: Irradiance D $1000 \mathrm{~W} / \mathrm{m} 2$, Temperature D $25{ }^{\circ} \mathrm{C}$, the load power PL D 2:5 kW. The DC bus voltage Vbusis controlled at the preset value Vbus* D $500 \mathrm{~V}$ as shown in Fig. 5.4 (a). In this scenario the maximum charging currentloop is enabled and the MPPT loop is disabled, and the batterycharging current is controlled as $i *$ b D 30 A, which is shown in Fig. 5.4 (d). From Fig. 5.4 (b) and Fig. 5.4 (c), the PV would notoperate at the maximum power point in this scenario, in orderto achieve the power balance of the system.

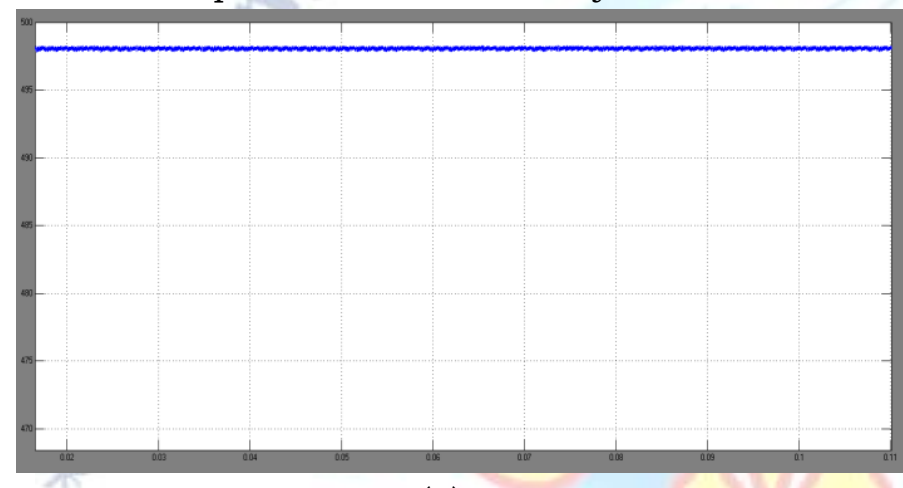

(a)

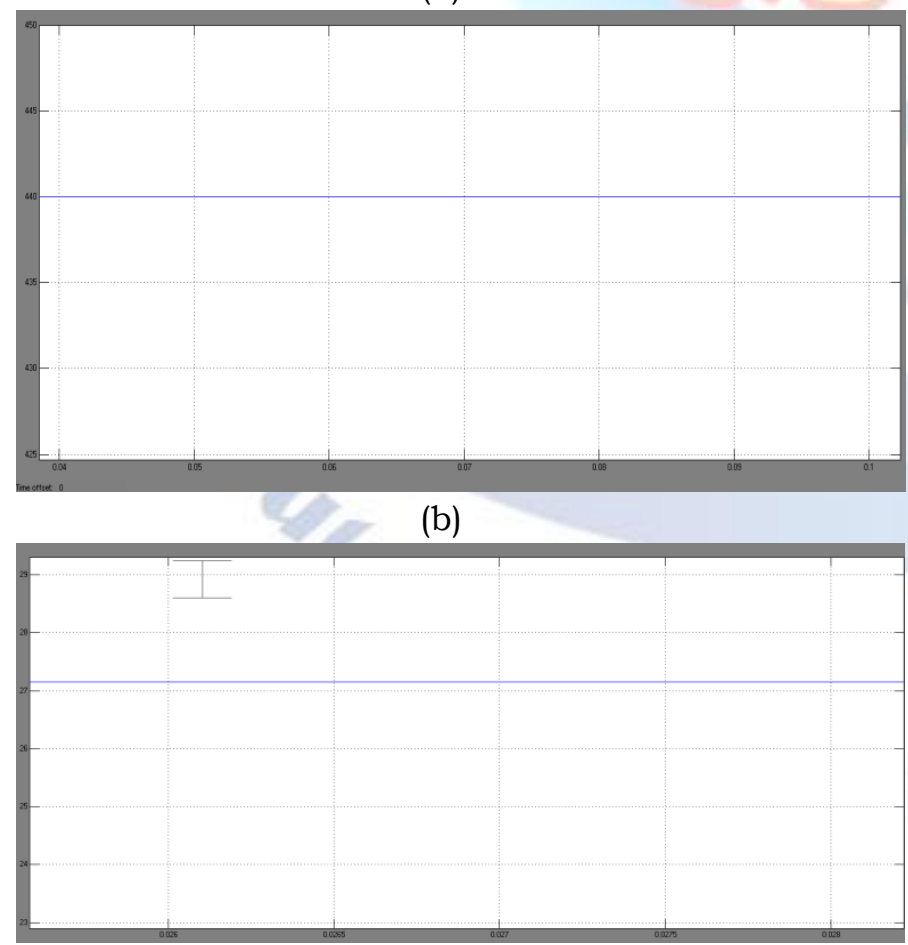

(c)

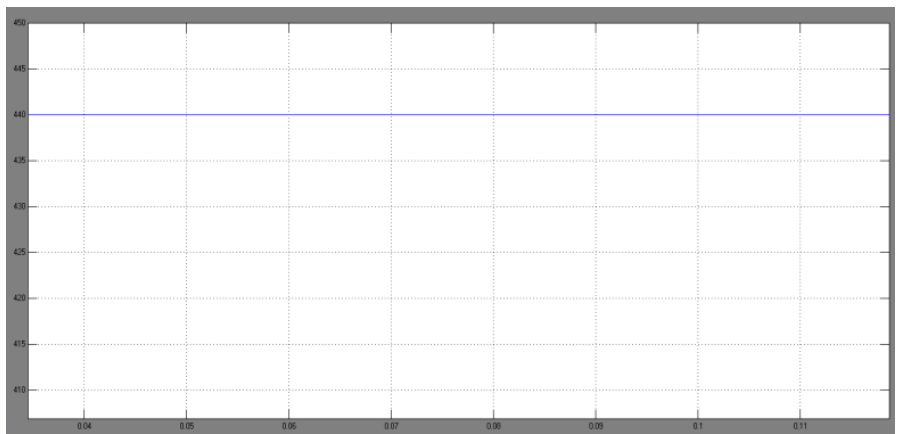

(d)

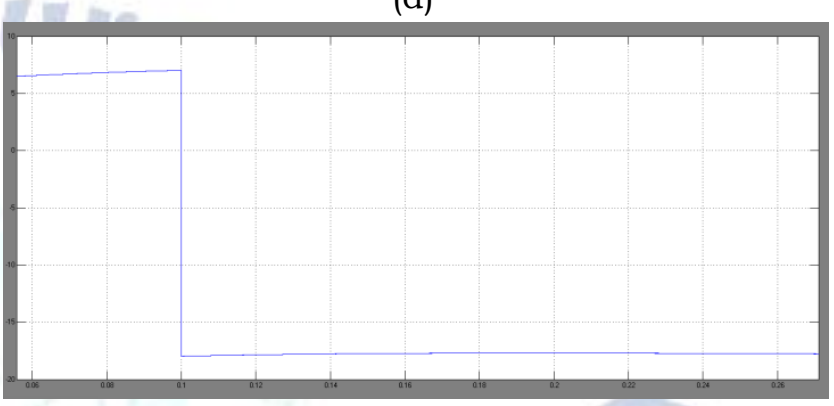

(e)

FIGURE 5.4. Simulation results with irradiance dropping from $1000 \mathrm{~W} / \mathrm{m} 2$ to $500 \mathrm{~W} / \mathrm{m} 2$ at t D $2 \mathrm{~s}$. (a) DC bus voltage Vbus; (b) PV voltage VPV; (c) PV current IPV; (d) PV reference voltage Vref; (e)

Battery charging current ib.

The dynamic performance of the system with the irradiancedropping from $1000 \mathrm{~W} / \mathrm{m} 2$ to $500 \mathrm{~W} / \mathrm{m} 2$ at $\mathrm{t} D 2 \mathrm{~s}$ is presented in Fig. 5.4. Other simulation conditions are as follows: Temperature D $25^{\circ} \mathrm{C}$, the load power PL D $8 \mathrm{~kW}$. The DCbus voltage Vbus keeps stable during the transition as shown in Fig. 5.4 (a). In this scenario the MPPT loop always takescharge of the control of the duty cycle D. From Fig. 5.4 (d), there is a slight rise of the PV reference voltage Vref, due to thevariation of the PV characteristic curve during the transition.From Fig. 10 (b) and Fig. 10 (c), MPPT is achieved withthe $\mathrm{PV}$ operating near the maximum power points of thetwo characteristic curves. From Fig. 10 (e), the irradiancedropping incident can be considered as a transition fromthe scenario 4 to the scenario 2 , as the battery operates inthe charging mode before the transition and operates in thedischarging mode after the transition.

(a) 


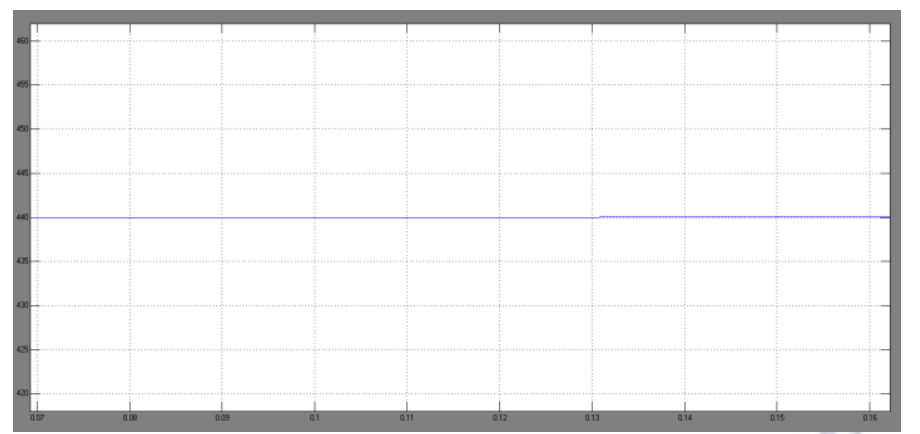

(b)

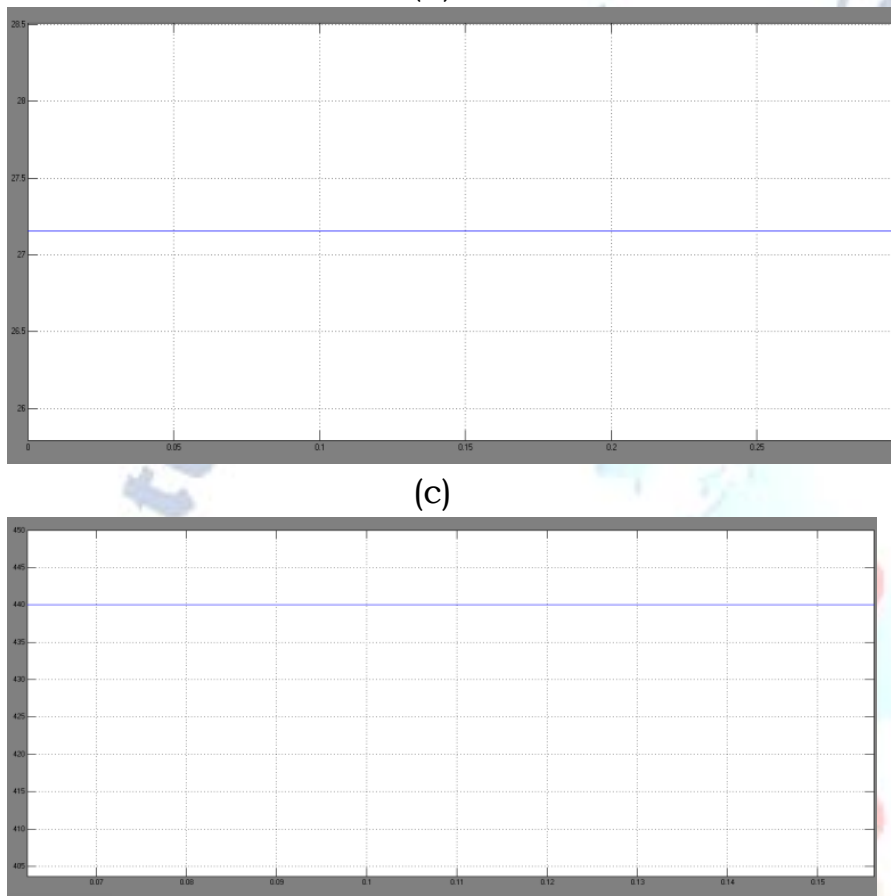

(d)

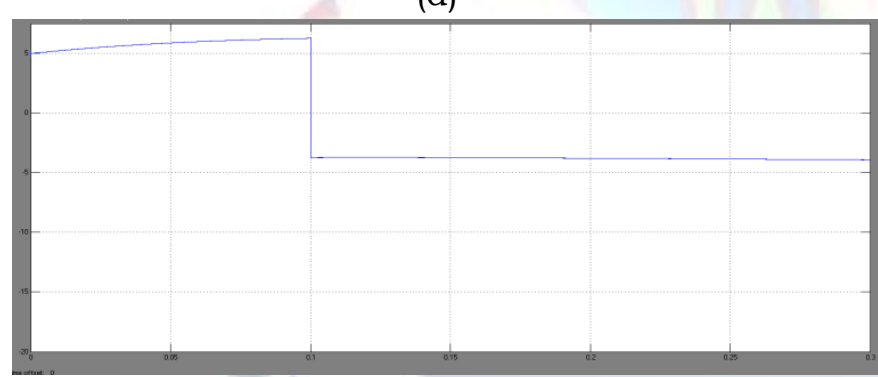

(e)

FIGURE 5.5. Simulation results with load power rising from $8 \mathrm{~kW}$ to $10 \mathrm{kWat} \mathrm{t} \mathrm{D} 2 \mathrm{~s}$. (a) DC bus voltage Vbus; (b) PV voltage VPV; (c) PV current

IPV;(d) PV reference voltage Vref; (e) Battery charging current ib.

The dynamic performance of the system with the load powerPL rising from $8 \mathrm{~kW}$ to $10 \mathrm{~kW}$ at t D $2 \mathrm{~s}$ is presentedin Fig. 5.5. Other simulation conditions are as follows: Irradiance D $1000 \mathrm{~W} / \mathrm{m} 2$, Temperature D $25^{\circ} \mathrm{C}$. The DC busvoltage Vbus keeps stable during the transition as shown in Fig. 5.5(a). In this scenario the MPPT loop is always enabled as shown from Fig. 5.5(b) to Fig. 5.5(d). Similar with theirradiance dropping incident discussed above, the load powerrising incident can be considered as a transition from theoperation scenario 4 to the scenario 2 as shown in Fig. 5.5(e).

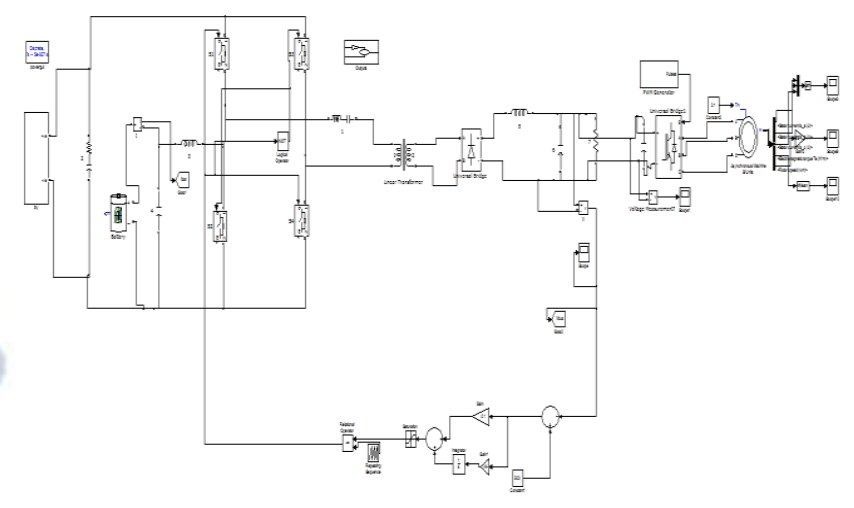

Fig 5.6 Simulink diagram of Proposed System power converter with Induction Motor drive

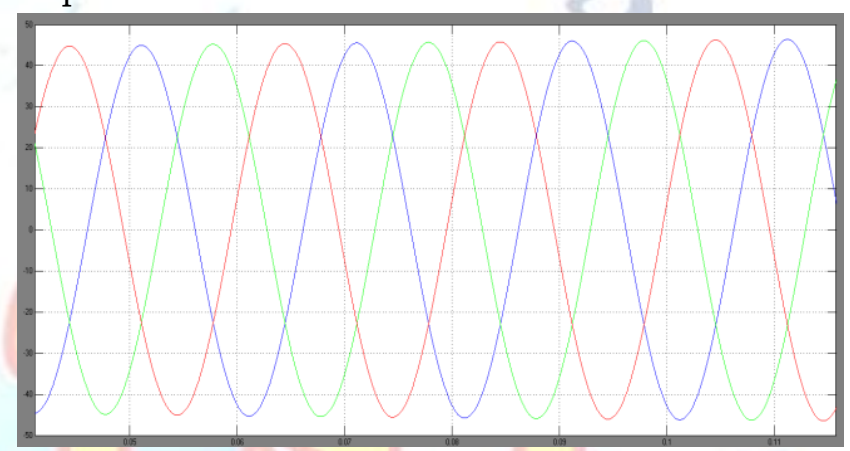

Fig 5.7 Simulation waveforms of Induction motor drive stator current characteristics

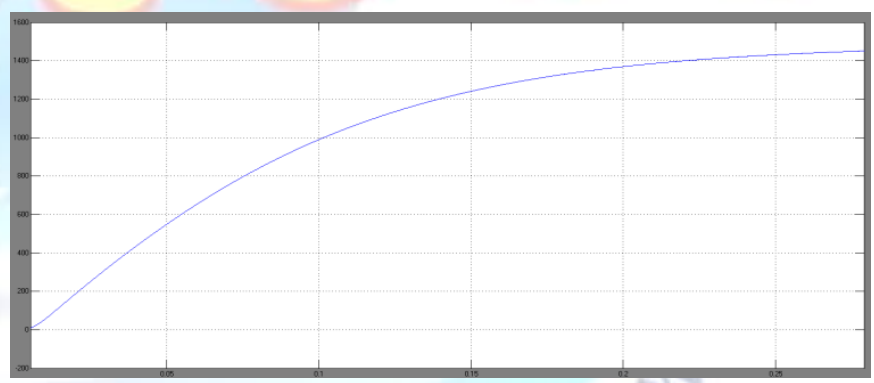

Fig 5.8 Simulation waveforms of Induction motor drive speed characteristics

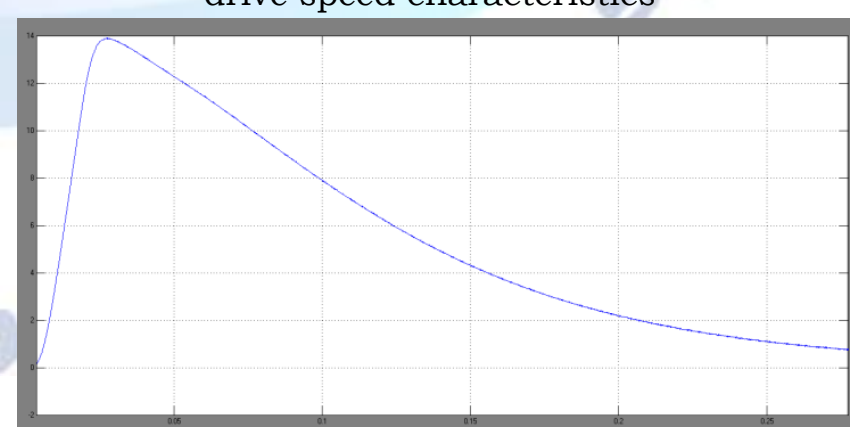

Fig 5.9 Simulation waveforms of Induction motor drive Torque characteristics

\section{Conclusion}

The microgrid combined with a renewable hybrid power system is a very promising, efficient, and 
clean power generation system. It can replace the conventional fuels easily. In this study, the an integrated three-port power converter as the interface for the PV/battery hybrid distributed power generation system is presented. It solves the problems of the individual source and supplies the load with sufficient and stable power. The PV array supplies the main power and the battery compensates for the power shortage because of shading and night time. The proposed system has advantages in terms of higher power density and reliability. The phase shift angle of the full bridge and the switch duty cycle are adopted as two control variables to obtain the required DC bus voltage and realize the power balance among three ports. Different operating scenarios of the system under various power conditions are discussed in detail and a comprehensive energy management and control strategy is proposed accordingly. The priority controller can enable one of the control loops in different scenarios to optimize the whole system performance, taking both the MPPT benefit and the battery charging/discharging management requirements into consideration.

\section{REFERENCES}

[1] F. Blaabjerg, Z. Chen, and S. B. Kjaer, "Power electronics as efficientinterface in dispersed power generation systems," IEEE Trans. PowerElectron., vol. 19, no. 5, pp. 1184-1194, Sep. 2004.

[2] J. M. Carrasco, L. G. Franquelo, J. T. Bialasiewicz, E. Galvan, R. Potillo,M. M. Prats, J. I. Leon, and N. Moreno-Alfonso, "Power-electronic systems for the grid integration of renewable energy sources: A survey," IEEETrans. Ind. Electron., vol. 53, no. 4, pp. 1002-1016, Jun. 2006.

[3] BP Statistical Review of World Energy, British Petroleum, London, U.K.,Jun. 2018.

[4] J. P. Barton and D. G. Infield, "Energy storage and its use with intermittent renewable energy," IEEE Trans. Energy Convers., vol. 19, no. 2,pp. 441-448, Jun. 2004.

[5] M. S. Whittingham, "History, evolution, and future status of energy storage," Proc. IEEE, vol. 100, pp. 1518-1534, May 2012.

[6] C. A. Hill, M. C. Such, D. Chen, J. Gonzalez, and W. M. Grady, "Batteryenergy storage for enabling integration of distributed solar power generation," IEEE Trans. Smart Grid, vol. 3, no. 2, pp. 850-857, Jun. 2012.

[7] Z. Yi, W. Dong, and A. H. Etemadi, "A unified control and power management scheme for PV-battery-based hybrid microgrids for both gridconnected and islanded modes," IEEE Trans. Smart Grid, vol. 9, no. 6,pp. 5975-5985, Nov. 2018.

[8] H. Mahmood, D. Michaelson, and J. Jiang, "Decentralized power management of a PV/battery hybrid unit in a droop-controlled islanded microgrid,"IEEE Trans. Power Electron., vol. 30, no. 12, pp. 7215-7229, Dec. 2015.

[9] K. Sun, L. Zhang, Y. Xing, and J. M. Guerrero, "A distributed controlstrategy based on DC bus signaling for modular photovoltaic generation systems with battery energy storage," IEEE Trans. Power Electron.,vol. 26, no. 10, pp. 3032-3045, Oct. 2011.

[10] S. Adhikari and F. Li, "Coordinated V-f and P-Q control of solar photovoltaic generators with MPPT and battery storage in microgrids," IEEETrans. Smart Grid, vol. 5, no. 3, pp. 1270-1281, May 2014.

[11] S. K. Kollimalla, M. K. Mishra, and N. L. Narasamma, "Design and analysis of novel control strategy for battery and supercapacitor storage system, "IEEE Trans. Sustain. Energy, vol. 5, no. 4, pp. 1137-1144, Oct. 2014.

[12] S. Wen, S. Wang, G. Liu, and R. Liu, "Energy management and coordinated control strategy of PV/HESS AC microgrid during Islanded operation," IEEE Access, vol. 7, pp. 4432-4441, 2019.

[13] W. Jiang and B. Fahimi, "Multiport power electronic interface-Concept,modeling, and design," IEEE Trans. Power Electron., vol. 26, no. 7,pp. 1890-1900, Jul. 2011.

[14] H. Krishnaswami and N. Mohan, "Three-port series-resonant DC-DCconverter to interface renewable energy sources with bidirectional loadand energy storage ports," IEEE Trans. Power Electron., vol. 24, no. 10,pp. 2289-2297, Oct. 2009.

[15] H. Tao, J. L. Duarte, and M. A. M. Hendrix, "Three-port triple-half-bridgebidirectional converter with zero-voltage switching," IEEE Trans. PowerElectron., vol. 23, no. 2, pp. 782-792, Mar. 2008.

[16] Z. Qian, O. Abdel-Rahman, and I. Batarseh, "An integrated four-portDC/DC converter for renewable energy applications," IEEE Trans. PowerElectron., vol. 25, no. 7, pp. 1877-1887, Jul. 2010.

[17] H. Al-Atrash and I. Batarseh, "Boost-integrated phase-shift full-bridgeconverter for three-port interface," in Proc. IEEE Power Electron. Spec.Conf., Jun. 2007, pp. 2313-2321.

[18] W. Li, J. Xiao, Y. Zhao, and X. He, "PWM plus phase angle shift (PPAS)control scheme for combined multiport DC/DC converters," IEEE Trans.Power Electron., vol. 27, no. 3, pp. 1479-1489, Mar. 2012.

[19] T. Esram and P. L. Chapman, "Comparison of photovoltaic array maximumpower point tracking techniques," IEEE Trans. Energy Convers., vol. 22,no. 2, pp. 439-449, Jun. 2007.

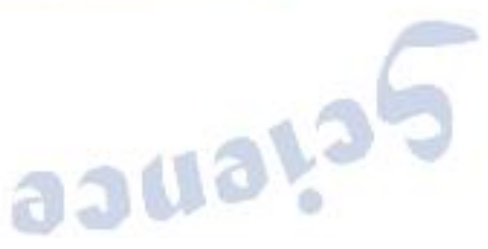

